\title{
Study of Energy Efficiency Solutions for a Smart Water Heating System
}

\author{
Najat Abdeljebbar, Lab LRI, National Higher School of Electricity and Mechanics, Morocco \\ Abdelwahab Haddaoui, Lab LRI, National Higher School of Electricity and Mechanics, Morocco
}

\begin{abstract}
The preservation of natural water and electricity resources is essential for the development of smart cities. Indeed, water and electricity are highly dependent and must be analyzed together to improve the energy efficiency. This article is about the study of the integration of renewable energy and smart solutions in a water heating system. The existing system uses mainly heat pumps to cover the most of the hot water needs. The purpose of this work is to explore possible solutions to optimize the electricity and the water consumption of the installation.
\end{abstract}

\section{KEYWORDS}

Energy Efficiency, Solar Energy, Thermal Panels, Water Heating System

\section{INTRODUCTION}

Located in North West Africa, Morocco enjoys a privileged geographical position, a varied climate and two sea fronts facing west on the Atlantic Ocean and north on the Mediterranean Sea. However, the country's sustained economic development over the past decades has nevertheless had significant impacts on the environment, generating pressures on natural resources in addition to those resulting from urbanization, population growth and climate change. Therefore, a certain number of precautions must be taken in order to optimize the energy efficiency by minimizing the consumption of water and electricity and promoting the use of renewable energies. Indeed, energy efficiency is a priority in the national energy strategy: the ambition is to save 12\% of energy consumption in 2020 and $15 \%$ in 2030. In this context, energy efficiency action plans have been implemented in all key sectors, in particular transport, industry and building (Renewable Energy, Ministry of Industry, Investment, Trade and the Digital Economy, n.d.). In this context, the use of solar thermal energy for water heating system production is one of the major challenges in the transition to energy-efficient building.

The purpose of this work is, in the first part, to study the possibility to add solar panels to the existing water heating system of a traditional Hammam, the objective is to optimize its energy efficiency and minimize the water-related energy consumption. In the second part, we focused on reducing water consumption by proposing the integration of the smart water grid.

\section{DESCRIPTION OF THE EXISTING SYSTEM}

The water heating system is used to supply a traditional Moroccan Hammam. This system uses 3 heat pumps to produce hot water at about $60^{\circ} \mathrm{C}$ with a backup made with an electrical resistance. The Hammam has three rooms with different temperatures in addition to showers. The consumption

This article, published as an Open Access article on January 11, 2021 in the gold Open Access journal, International Journal of Web-Based Learning and Teaching Technologies (converted to gold Open Access January 1, 2021), is distributed under the terms of the Creative Commons Attribution License (http://creativecommons.org/licenses/by/4.0/) which permits unrestricted use, distribution, and production in any medium, provided the author of the original work and original publication source are properly credited. 
of this Hammam is estimated at about 30,000 1/d, with an energy requirement estimated at 4000 Mwh per year.

Our work aims to reduce the electrical energy consumption of the system by using solar energy. Indeed, this kind of energy is an unavoidable option for the minimization of dependence on fossil energy sources and for the reduction of gas emissions. Solar energy is considered as clean, available and inexhaustible and it can be converted using existing technologies in order to satisfy the human needs. In fact, photovoltaic technology converts solar energy into electrical one, while thermal solar technology recovers energy from the sun to provide heat. That heat can be used for hot water production, or air conditioning.

In the following paragraph, we will focus on improving energy efficiency and reducing the electrical energy consumption of the water heating system of the traditional Hammam, the proposed solution is the addition of thermal solar system.

\section{INSERTION OF SOLAR THERMAL SYSTEM}

\subsection{Description of a Solar Thermal System}

Solar thermal system is generally divided into 5 subsystems (Ministry of Housing and Urban Policy, n.d.):

- Collection: a set of solar collectors that transform solar radiation into thermal energy.

- Transfer: a solar hydraulic circuit that connects the collectors to each other and distributes energy throughout the entire system.

- Storage: solar storage tanks.

- A back-up system (electric): it provides the necessary energy to guarantee at all times the hot water needs, especially during periods of low sunlight.

- Regulation: A device for regulating, measuring and controlling the system.

\subsection{Study of the Feasibility of Integration of the Solar Thermal System}

The reduction of the energy consumption due to the use of solar energy depends on several criteria as the climate, the location of the solar collectors, the size and design of the system; it depends also of the choice of equipment and its maintenance. Therefore, it is necessary to seek the best economic adjustment of the size of solar equipment to the needs to be satisfied. In fact, the design of a solar system first involves determining the collector surface area according to the volume and profile of hot water consumption. By simplifying the problem, it is a question of determining how many collectors of a certain brand and type are required to achieve the target energy production for a given installation.

The functioning of the solar water heating system is simple. During sunny hours, the primary circuit of the solar collectors increases its temperature and transfers the collected heat to the storage tanks to coil-type heat exchangers located inside or outside the tanks. The fluid flow in the solar circuit is carried out under pressure by a pump and a control system according to the heating capacity available at any time. It must be taken into account that as the coverage rate increases, the temperature of the fluid in the collector also increases and this causes the decrease in the efficiency of the sensor. In addition, high coverage means that the temperature in the tanks will often reach the maximum temperature, causing the plant to shut down (Ministry of Housing and Urban Policy, n.d.).

The implementation and design of a solar thermal system depends on several major factors, including:

- Hot water needs: a correct estimation of hot water needs is crucial to the optimal design of the system. 
- Desired solar coverage objectives: Solar systems cover on average between 40 and $60 \%$ of annual needs of hot water. During the summer months, with more solar radiation and a marginally higher cold water temperature, the system can easily cover between 70 and $80 \%$ of the needs.

- Weather data: The solar radiation available in the project area and, to a lesser extent, the average outside temperature and the temperature of the cold water network influence the energy performance of the system.

- The surface area of the panels: it will depend on the surface area, orientation and shape of the place of installation, as well as the possible existence of obstructions and shadows generated by adjacent buildings.

- Equipment characteristics: The specific characteristics of solar panels have a major influence on the expected annual energy performance of the system.

\subsection{Dimensioning of the Thermal Solar System}

The Hammam is in the city of Casablanca, which is located on the Atlantic coast in North-West Africa. $33^{\circ} 35$ North Latitude, $7^{\circ} 25$ West Longitude (Casablanca Urban Agency, n.d.).

That traditional Hammam has hot water needs at $60^{\circ} \mathrm{C}$. These needs are provided by three heat pumps. Our goal is to insert solar thermal panels at the existing facility to reduce power consumption. To do this, we took into consideration the different criteria and constraints of the building.

Indeed, the installation of the solar system involves the use of part of the building's surface area to install the various components.

In particular, it is necessary to plan: A roof space for the installation of solar panels, a surface area for the installation of individual solar storage tanks inside the building, a technical room for the location of the hydraulic components of the solar primary circuit and for the passage of the panels connection pipes to the storage tanks.

In our case, the available surface area of the roof conditions the calculation and sizing of the solar panels that can be installed. The surface area dedicated to the installation of the panels is about 1000 $\mathrm{m} 2$, facing south with no shading or neighboring obstacles. In addition to the space of thermal panels and the storage tanks, the hydraulic circuit requires other components that must be located inside the building in a technical room located near the thermal panels. Among these components, we find:

- A circulation pump, sized for the nominal flow and the required operating temperature.

- A set of safety elements, consisting of at least one safety valve and an expansion tank whose volume is sufficient to collect the fluid present in the circuit.

- A differential control system.

- Valves and measuring instruments (thermometers, manometers, etc.).

The choice of the thermal panel's type: the choice depends on several factors, first the type of application, then the distribution of needs throughout the year, the target temperature, the price, the guarantees offered or the conditions for installing the panels on the building (aesthetic integration, possible orientation and inclination, available spaces). In any case, the plan-type solar panel is by far the most commonly used to produce hot water in temperate climates. In fact, in the climatic conditions of Morocco and with the temperature levels required for the production of hot water, plan-type thermal panels are the best option (Ministry of Housing and Urban Policy, n.d.). That's why we have opted for plan panels.

The positioning of thermal panels: The thermal panels are laid in two rows taking into consideration the required distances. In fact, in the case of close obstacles of constant height, the effect on energy production can be considered to be small if the distance between the obstacles and the panels is greater than a value that can be calculated according to the following formula (Ministry of Housing and Urban Policy, n.d.): 
$\mathrm{d}>\mathrm{h} / \tan \alpha$ or $\mathrm{d}>\mathrm{k} \cdot \mathrm{h}$

with: $\mathrm{k}=1 / \tan \alpha \mathrm{h}$ : is the relative height of the obstacle measured from the lower edge of the solar collector. $\alpha$ : is the angle of the solar height at noon solar of the winter solstice.

Taking into consideration the different criteria, we had calculated and realized a simulation of the thermal solar system.

The storage volume planned to ensure the storage of hot water produced from solar panels is 30 $\mathrm{m} 3$ (3 storage tanks of $10 \mathrm{~m} 3$ ) with a maximum storage temperature of $90^{\circ} \mathrm{C}$.

The thermal installation is connected by external exchangers. The functioning of the system is designed in such a way that priority is given to thermal panels over heat pumps to improve the energy efficiency of the installation.

\subsection{Simulation and Results}

The climatic conditions in Casablanca are particularly favorable for taking advantage of solar energy. The abundance of this renewable, indigenous and emission-free energy resource will allow this option to play a key role in the future, characterized by the need to reduce the country's energy dependence and $\mathrm{CO} 2$ emissions.

The use of thermal solar energy in a moroccain traditional Hammam is only in its beginning, and the number of projects is still very small.

The simulation result shows clearly a significant saving in power. In fact, the proposed solution would save around $20 \%$ of energy.

The integration of renewable energies into the Hammam's water heating system makes it possible, based on the simulations carried out, to optimise the system's energy efficiency.

However, the energies in electricity and water are strongly linked and must both be integrated into a single optimization system to transform the old installation into an efficient and intelligent one.

Table 1. Calculation of minimum distances between elements to avoid significant shading

\begin{tabular}{|c|c|}
\hline Latitude & $\begin{array}{c}33,35^{\circ} \text { (3rd report on the state of the environment of } \\
\text { Morocco, 2015) }\end{array}$ \\
\hline $\mathrm{k}$ & $\begin{array}{c}1.51 \text { (Coefficient k table for calculating the separation } \\
\text { distance of an obstacle, n.d.) }\end{array}$ \\
\hline $\mathrm{h}$ & $0,81 \mathrm{~m}$ \\
\hline $\mathrm{d}$ & $1.25 \mathrm{~m}$ \\
\hline
\end{tabular}

Table 2.Thermal panel characteristics

\begin{tabular}{|l|l|}
\hline \multicolumn{1}{|c|}{ Location } & \multicolumn{1}{c|}{ Casablanca } \\
\hline Available surface area & $1000 \mathrm{~m} 2$ \\
\hline Panels type & Plan \\
\hline Number of panels & 364 \\
\hline installed surface area of panels & $913,64 \mathrm{~m} 2$ \\
\hline panel tilt angle & $20^{\circ}$ \\
\hline panel orientation & South \\
\hline
\end{tabular}


Table 3. Evolution of the percentage of electrical energy saved

\begin{tabular}{|l|c|c|c|c|c|c|c|c|c|c|c|c|}
\hline & Jan & Feb & March & April & may & June & July & Aug & Sept & Oct & Nov & Dec \\
\hline $\begin{array}{l}\text { Energy } \\
\text { saving } \\
\text { rate in } \%\end{array}$ & 14,0 & 17,2 & 20,9 & 24,2 & 25,6 & 26,7 & 28,1 & 27,8 & 25,5 & 20,4 & 15,8 & 12,3 \\
\hline
\end{tabular}

\section{SMART MANAGEMENT OF WATER}

Water in Morocco faces many challenges, including water scarcity, irregular rainfall and uneven spatial distribution. These challenges are being accentuated by the effects of climate change and, over the years, the indicators have shown a situation that is sometimes critical and even alarming (Coefficient k table for calculating the separation distance of an obstacle, n.d.). Therefore, to optimize water consumption of the Hammam, the management of water must be smart and efficient.

Therefore, we need to use the Smart Water Grid (SWG). The latter can be defined as an advanced and smart water management system. Indeed, it integrates Information and Communication Technologies (ICT) into the management of the distribution system (Le matin, n.d.).

The use of SWG as a means of managing the water network makes it possible to control, monitor and optimize the consumption of this resource. Thanks to the SWG, water quality, pressure and flow can be monitored, the risk of pipe bursting can be prevented and leaks can be detected .

In addition, the use of SWG provides access to various data and allows real-time monitoring and management of consumption. The SWG is designed to address the major issues encountered in water management on both the distribution and consumption sides. It also provides better visibility and a high level of control, not only on consumption, but also on the condition of the installations, thus facilitating equipment maintenance, fault detection and incident forecasting.

Advantages of Smart Water Grid: The smart water grid is used ensure the preservation and efficient management of the water resource. To this end, it must meet the requirements necessary for the water distribution process in the Hammam. The five criteria of reliability, safety, efficiency, security and availability are therefore an essential asset for the implementation of the SWG.

By using the latest technologies, the SWG makes it possible to collect a very large amount of data, to ensure real-time monitoring, to react more quickly, and above all to anticipate and anticipate any incident or anomaly in the system. As a result, we have defined the three main advantages of the SWG: Avoiding leaks demand controlling, and quality management.

- Avoiding leaks: One of the major problems of water distribution networks is the appearance of leaks. These leaks not only impact the environment but also generate significant losses and increased direct and indirect costs. The use of SWG makes it possible to detect leaks more quickly, prevent any incident or anomaly, plan and schedule maintenance or replacement of equipment and pipes. Using several methods, the SWG provides better visibility and a high level of control from the source to the end use. Water leaks or losses can be evaluated as the difference between the volume of water at the entrance to the network and the authorized consumption. These leaks may be apparent as those due to metering inaccuracies, or reel leaks caused by pipe bursting, or overflows (Choi et al., 2016). Water reel leaks result from deterioration of the water distribution system, which could be caused by environmental or physical factors related to the condition of pipes and equipment, or operational factors such as pressure and flow velocity. As a result, leak detection is a major concern to improve the energy efficiency and ensure the preservation of water resources.

- Demand controlling: This approach focuses on controlling demand through the implementation of technological and economic measures. Water demand management is also essential for the 
assessment of water prices and investments. Generally, the total water demand differs because of many reasons and several approaches are used in the management of this demand.

- Quality Management To control water quality, several instruments are used. Indeed, a number of real-time water quality monitoring sensors currently exist on the market:Conventional sensors that directly measure specific water quality parameters such as $\mathrm{pH}$, turbidity and conductivity. Sensors that detect any deviation from the generic properties of the water (such as optics) to cover a broader spectrum of contaminants. Biosensors that monitor the behaviour of living organisms in water to assess the toxicity of contaminants in water samples.

\section{CONCLUSION}

The global annual irradiation in Morocco is in most regions between 1800 and $2000 \mathrm{kWh} / \mathrm{m}^{2}$.an. It is slightly lower, about $1700 \mathrm{kWh} / \mathrm{m}^{2}$.year, in some coastal areas and higher, about $2100 \mathrm{kWh} /$ $\mathrm{m}^{2}$.year, in the south (Ministry of Housing and Urban Policy, n.d.).

This important energy potential can be used to heat water for sanitary purposes and can lead to substantial savings in electricity consumption. Therefore, we worked on the example of a Moroccan Hammam that uses heat pumps with a backup made by electrical resistances. Our objective was to study the feasibility of integrating thermal solar energy into the existing system in order to improve its energy efficiency.

To do this, we took into consideration the different parameters and constraints of the installation and we proposed the addition of 364 thermal panels on the useful space on the roof of the Hammam. The simulation of our study clearly showed that our solution is very useful and allows reducing $20 \%$ of the consumption of energy in the Hammam. However, reducing the electricity consumption of the water heating system is only the first step in the process of improving the energy efficiency of the installation. Indeed, water management in this kind of installation is a major challenge. Therefore, the installation must be equipped with a Smart Water Grid. In fact, smart water grid differs from the traditional one by integrating technology into the water management systems. The implementation of SWG technology helps to have an optimized and efficient water management, it also ensure continuity, stability and safety of use. Indeed, by using SWG, water distribution are automated, monitored and controlled by sensors. Using ICT information and communication technologies (Internet of Things, Cloud Computing, Big Data Analysis), huge amounts of data are collected, stored and transmitted for real-time analysis.

The water and electricity resources of the Hammam are inseparable. Therefore, we must be taken them both into consideration in order to optimize the energy efficiency of the installation. In fact, through the use of solar thermal energy and SWG, the energy efficiency of the installation can be significantly improved. Indeed, the reduction in water-related electricity consumption and water consumption allows the preservation of natural resources and the environment. 


\section{REFERENCES}

43rd report on the state of the environment of Morocco. (2015). Ministry Delegate to the Minister of Energy, Mines, Water and Environment, in charge of the environment. http://www.environnement.gov.ma/PDFs/Rapportreem.pdf

Casablanca Urban Agency. (n.d.). https://www.auc.ma/auc.asp?codelangue=23\&info=1315\&het_r=

Choi, G. W., Chong, K. Y., Kim, S. J., \& Ryu, T. S. (2016). SWMI: new paradigm of water resources management for SDGs. Smart Water.

Coefficient k table for calculating the separation distance of an obstacle. (n.d.). Guide-Chauffe-Eau-Solaires. Ministry of Housing and Urban Policy, Directorate of Quality and Technical Affairs. http://www.mhpv.gov.ma/ wp-content/uploads/2018/03/GUIDE-CHAUFFE-EAU-SOLAIRES.pdf

IWA Task Force. (2003). Water Loss Assessing non-revenue water and its components: a practical approach. WATER21. http://www.pacificwater.org/_resources/article/files/IWA

Le matin - problématique de l'eau au Maroc L'heure est à l'action / Changement climatique Ces dangers qui pèsent sur les ressources hydriques du Maroc. (n.d.). https://lematin.ma/journal/2017//heure-est-a-laction

Ministry of Housing and Urban Policy. Drectorate of Quality and Technical Affairs. (n.d.). http://www.mhpv. gov.ma/wp-content/uploads/2018/03/GUIDE-CHAUFFE-EAU-SOLAIRES.pdf

Renewable Energy, Ministry of Industry, Investment, Trade and the Digital Economy. (n.d.). http://www.mcinet. gov.ma/fr/content/energies-renouvelables 